\title{
Scaffolding Instruction in Virtual Language Learning
}

\author{
Zhengxia Liu \\ Faculty of Foreign Languages, Huaiyin Institute of Technology, Huai'an, China \\ Jie Hua \\ Faculty of Foreign Languages, Huaiyin Institute of Technology, Huai'an, China \\ Zixu Zhang \\ School of Control \&Computer Engineering, North China Electric Power University, Beijing, China
}

\begin{abstract}
In the digital age, language learning by way of Internet technology has been popular among learners and the traditional classroom teaching is being replaced by virtual learning due to the pandemic. The upcoming technologies presenting a number of challenges for language teachers are changing teaching and learning environment. The models of virtual language learning require learners to be more cooperative to construct their own learning pace. A new scaffolding instruction is booming in terms of language education to promote linguistic and academic development. Different from the traditional classroom education, it is necessary for instructors to provide scaffolds for the students to enter the situation, set up a support and explore the differences with independence. The effect of good scaffolding instruction can optimize the virtual language learning in such aspects as cooperative learning and quality control and facilitate the learners' development on critical thinking with the ultimate purpose of independent learning.
\end{abstract}

Index Terms — scaffolding instruction, virtual language learning, cooperative learning

\section{INTRODUCTION}

Nowadays, delivering teaching through Internet technology has become a fashion, making the language learning engaging and fulfilling online. The traditional classroom teaching is being replaced by virtual learning due to the pandemic and the upcoming technologies are changing teaching and learning environment. However, when we look from the perspective of learning theory, it is desirable to note that the virtual language learning models require learners to be more cooperative to construct their own learning pace. This means there is an opportunity for instructors to construct a cooperative and learner-centred virtual learning environment.

In traditional classroom, information technology serves as a tool to assist and control language learning in a formal learning environment. In an informal learning environment, similar to virtual classroom, how to keep balance between facilitating learning and allowing learners to be independent will be an important topic to be discussed. Also, more importantly, the teaching strategy to be applied in virtual language learning should appeal to the learners' academic, emotional, and cognitive needs since the instructors are no longer dominating the learning process. There is an urgent need to adapt to this situation. In this paper, it is essential for teachers to adopt a new model of scaffolding to support virtual language learners pedagogically to achieve their potential, develop language knowledge deeply and also engage in academic activities actively.

\section{SCAFFOLDING InSTRUCTION AS A NEW TEACHING STRATEGY}

Language education is not only a matter of cognitive development but also an experience based on social development. Thus, classroom learning consists of the cognitive and the social process, which generally involves an interaction or an engagement with other language learners in a virtual environment. Many of these changes pose challenges to language instructors. The teaching strategies in a more user-centred way directly satisfy learners' needs and also the learning process appeals to the emotional needs of language learners, who feel isolated compared with face-to-face communication. In addition, the teaching strategy in virtual learning environment must meet the cognitive needs of learners by providing a learning environment that may relate to different learning styles and generally be more engaging. The application of scaffolding instruction as a new teaching strategy in virtual language learning environment raises issues about cooperation learning, quality control and how to facilitate the language development based on critical thinking with the ultimate purpose of independent learning.

\section{A. Scaffolding Instruction in the Traditional Language Teaching}

In his sociocultural theory, Lev Vygotsky defines his concept of "ZPD" as "The zone of proximal development", the 
distance between what children can do by themselves and the next learning objective that they can achieve with competent assistance" (Vygotsky, 1978). Based on the concept, Bruner (1983) originated "scaffolding" as a teaching strategy, which refers to the more knowledgeable one provides scaffolds or supports to facilitate the other's learning process. In language learning, the scaffolding instruction serves as the role of teachers and others in supporting the learners to move forward the learning development to the next stage or level. According to Ruiz (2000), the scaffolding process is temporary. When the learner's competence reaches the next level, the scaffolds will be withdrawn and reduced. Therefore, new supports or scaffolds will be constructed as learners' abilities and competences increase during the next learning process. The role of the scaffolding instruction turns out to be supportive and the purpose of the scaffolding instruction aims on language learners' independent learning.

In classroom educational setting, such scaffolds as models, cues, prompts, hints, partial solutions, think-aloud modeling and direct instruction scaffolds may be adopted by instructors (Rubin, 1975). Language instructors make full use of the models of scaffolding to aid language learning and practising. In virtual learning process, a Scaffolding as a Teaching Strategy may be applied as the tools to prompt the students to complete the next step of the task in learning a language. Questions raised by instructors may also be used as scaffolds to help students solve a problem or fulfil a more difficult task. With the right response from the learners, language instructors may move forward with more complicated tasks for them to practise language with fluency and accuracy. If the learners fail to respond to this type of questioning scaffold, teachers may adopt the new scaffolding of vocal hints to suggest a new solution to the problem. Teachers should proceed with a more intrusive verbal prompt to remind the student that there is a rule. When the learners can complete the task without the instructors' vocal hints or develop his or her own language ability to deal with the problem, it is the high time that the teachers remove the scaffolding from language education classroom for them to solve the problem independently or proceed to the next advanced learning process with new scaffolding strategies.

A variety of factors such as the classroom setting, the teacher's facial expression, body language and even peers' eyesight contribute to the language production and application in the traditional language instruction. The verbal and non-verbal communication serves as a scaffolding teaching strategy in language input and output, which benefits the learners in developing their language competence and performance. Also, Scaffolding Instruction can play a great role in helping English beginners learn language points, grammar rules, and special cases with real-time response. The traditional classroom teaching of grammar is to directly present the knowledge of grammar rules to students, and students belong to passive acceptance of grammar knowledge. It is easy for students to forget or feel confused with the instant input. It is uncertain for instructors to monitor whether language learners memorize or understand grammar knowledge deeply. Consequently, it will take a lot of time for both teachers and students to strengthen the mastery of grammar knowledge, which triggers a negative learning attitude for learners. If the questions can not be solved in time, it is more likely to influence the learning process of grammar knowledge. Thus, the whole language learning and teaching process is passive and negative with more energy, time and efforts in the traditional models of language learning.

If we adopt the new model of Scaffolding Instruction in language teaching, we do not directly put the grammar rules on the table. First of all, teachers help students recall the grammar knowledge they have learned before and then move on to the new rules by reviewing the former knowledge they have mastered. For example, when learning the past tense, the students are required to talk about what they were doing yesterday or last week. When students do not formally learn the past continuous tense, they use their existing knowledge to express what is going on in the past. Students may not produce the grammatically correct answer, which is the need for teachers to provide support to students, such as reminding students of the wrong parts and guiding them to change their sentence patterns. It can also be practicable for students to provide supports for each other to answer questions and correct their expressions in a cooperative mode. After students have roughly mastered how to express what is happening at a specific time in the past in this new environment, it is natural for teachers to formally introduce new grammar. With the supportive learning evolving into independent learning, the scaffolding model disappears and continues to play a new role in the more advanced process of language instruction so that students will better learn new knowledge and achieve better learning results with the help of the previously provided support. During this instruction process, the knowledge learned before as a scaffolding model assist the presentation of the new grammar. Besides, both the teacher's support and the peer learners' cooperation work as the scaffolding instruction for the learners to reach the new stage of independent language learning.

\section{B. Scaffolding Instruction in Virtual Language Learning}

Virtual language learning is different from the above traditional classroom education, where educators and learners can interact with each other face to face. Similar to the process of traditional language learning, it is still necessary to provide scaffolds for the students to engage in cooperative learning in virtual language setting. In this type of online environment, students help each other in small groups but they still need some assistance. Even though it is helpful for instructors to utilize the scaffolding strategy to engage students in research work and online learning, learners may have more initiatives in cooperative learning. They are free to practise language and complete the language tasks in group work or pair work. In this context, the scaffolding of cooperation prompts organized and focused language learning for facilitating students' social-cultural cognition. Thus, it is assumed that the organizations and focuses are the unique components of scaffolding in this virtual classroom. The teachers are responsible for providing guidance and instructions in need but the learners themselves produce the final structure and accuracy through their independent 
research. In a chapter on "Scaffolding for Success", Jamie McKenzie (1999) provides a visual image analogy of how scaffolding works, "The workers cleaning the face of the Washington Monument do not confuse the scaffolding with the monument itself. The scaffolding is secondary. The building is primary." Through scaffolding teaching, with the help of teachers, language learners can eliminate the difference, which exists in "the nearest development area" of the Scaffolding Instruction. In effect, the essence of scaffolding is to use the conceptual framework of basic knowledge as a scaffold in the learning process. The basic links of scaffolding teaching in virtual language learning can be divided into the following three aspects:

1) Enter the situation

Instructors guide learners into a certain situation for the problems and provide necessary tools to solve problems by introducing the preceding materials to remind them of the knowledge they are familiar with in previous language learning. This process may be questions, hints, videos or resources they search ahead of the class. The preparation step of the language materials may interest them and also be easy for them to comprehend in virtual class.

2) Set up a support

This is the second step in which teachers guide students to solve the language problems by exploring into the situations. Firstly, teachers should help set goals and provide directions for learners to figure out the learning schedule. Under the guidance of the teachers, the learners will not be distracted or confused with the increasing complexity of the problems. Secondly, teachers should focus on the current learning content and provide students with the conceptual framework needed, which should be placed in the "Recent Development Zone" of learners. If the conceptual framework is beyond the learners, it is meaningless for them to explore into the problems. Thus, the learners' former language competence matters in the second step. Thirdly, teachers can guide the exploration of problem situations by making presentations, providing the prototypes of problem-solving and providing feedback for students during the process of problem-solving. Above all, the guidance of teachers should be gradually reduced with the enhancement of students' ability to independent problem-solving.

3) Explore with independence

At this stage, students decide their own problems and directions, choose their own methods and explore independently. At this time, different students may explore different problems in virtual environments and they may make use of different language materials to achieve their learning objectives. It does not mean that teachers lose control of the learners. Instead, teachers need to continue to provide support for students, such as reminding students of the wrong parts and guiding them to change their learning directions or plans by monitoring and controlling the language assessment by providing the correct example. It can also be advocated that students provide supports for each other to answer questions and correct their expressions in a virtual cooperative mode. After learners have roughly mastered how to deal with the learning process smoothly and solve the problems successfully in this new environment, they will be active to go ahead with the next learning schedule. The Scaffolding Instruction will repeat from the first step simultaneously to the next advanced learning task.

To sum up, Scaffolding Instruction in a virtual language learning environment should provide a conceptual framework for learners to construct their understanding of knowledge. The concepts in this framework are needed to develop learners' further understanding of problems. Therefore, complex learning tasks should be decomposed in advance into entering into the situation with their prior knowledge, setting up supports by decreasing the complexity of problems and guiding them to exploring into the tasks with independence in order to gradually deepen learners' language understanding.

\section{ThE APPLiCATION OF SCAFFOLDING InSTRUCTION IN ViRTUAL LANGUAGE LEARNing}

The application of scaffolding instruction in virtual language learning differs from the traditional instruction in classroom. In virtual language teaching, it is hard to make a lot of cooperation between teacher-student or peers due to the different space. Also, much quality control appears to be more essential since it is desirable for the teachers to assess the achievements in learning a language. What's more, language learners even ignore the significance of critical thinking in virtual learning environment. According to a research, Scaffolding Instruction is the effective approach to the dilemma with a lot of benefits. One of the primary benefits of scaffolding instruction in virtual language learning is that it engages the learner into the learning environment. They are not separated from the physical distance, which does not involve listening to information passively but prompting the learners to build on their new knowledge based on the prior research and cooperation. Also, this application of scaffolding instruction can provide a positive and effective assistance for those students who have low self-discipline and slow learning abilities, and can produce an accurate feedback for them to improve and speed their learning pace. Besides, the application of scaffolding instruction in virtual setting motivates the student to learn language in correspondence with their own schedule. What's more, this type of instruction can minimize the level of frustration to satisfy their special needs if the learners refuse to participate in cooperative learning in virtual learning setting.

\section{A. Scaffolding Instruction in Cooperative Learning}

In virtual language learning environment, scaffolding instruction provides a variety of activities and tasks to assist verbal and non-verbal communication: 1) to motivate the learners' interest; 2) to simplify the task to make it more 
achievable; 3) to provide some direction to focus on the goal; 4) to indicate clearly the difference between learners' work and desirable objectives; 5) reduce frustration and boredom in language learning; 6) to guide and clearly instruct the completion of the activity to be performed (Bransford, 1999). Also, Rogoff (1995) summarizes six characteristics of scaffolding instruction as models, cues, prompts, hints, partial solutions, think-aloud modeling and direct instruction (Gibbons, 2002). In applying the six rules in language instruction, the scaffolds can be decreased or removed gradually when the learners develop their own language ability into be independent learners. In the next stage of learning, the instructors provide scaffolding by engaging the learners into virtual cooperative learning. Learners develop their language learning by peer-to-peer communication in small groups while the instructors' support happens only when necessary. Virtual cooperative learning provides a space for self-regulating and self- monitoring, which both facilitate the virtual learning effects.

In virtual learning environment, the key to successful cooperative learning depends on the instructors' clear direction to reduce their confusion and anticipate problems they may encounter in virtual environment. Scaffolds for cooperative learners must meet their expectation to complete the language tasks and help understand the learning purpose. The scaffolding instruction also provides support and clarity in cooperative language learning but the learners construct the learning process by group work. The scaffolding is secondary but the learning process is primary (Moll,1990). When learners achieve the language competence, scaffolds must be removed step by step.

\section{B. Scaffolding Instruction in Quality Control}

In scaffolding instruction, educators may point out worthy sources to reduce confusion, frustration and time. The purposes of the scaffolding in virtual learning are to reduce learners' uncertainty, surprise and disappointment to eliminate difficulties in language and to motivate learning process. Pierce (1995) describes six roles of scaffolding instruction with two related to quality control. In language learning, scaffolding helps learners focus on tasks by providing structures and pathways for them to make decisions about which path to choose or what things to explore.

In virtual learning environment, learners can arrange their schedule and decide when to complete the designated task but they cannot wander off the path or ignore the directions. According to Donato (1994), instructors constantly monitor the learning process by distance control. Since expectations are clarified for the beginning of the learning activity, the assessment and feedback are displayed to the learners online, which boost learning process and help adjust the learning quality and efficiency.

The basis for all learning is quality control. The development of acquiring knowledge and learning ability is promoted by social interaction, which boosts the production of language. Consciousness, the notions of self and identity, physical skills and mental abilities originate in social interaction among instructors, learners, parents and children. It is supposed that human learning precedes a social nature when children grow into the intellectual life. (Vygotsky, 1978) Every function in the child's cultural development appears twice, on two levels, that is, the social level and the psychological level. The social level is the inter-psychological development for the language learners to control their learning process; while the psychological level motivates the learners to be more confident in terms of quality control, which turns out to be more intra-psychological. Both the social and psychological functions contribute to the language learning activities and facilitate quality control in virtual learning setting.

\section{Scaffolding Instruction in Critical Thinking}

The two different aspects of scaffolding instruction in critical thinking are the cultural function and the corresponding mental function. In the process of critical thinking, internalization is defined as a process of transformation, involving appropriation and reconstruction. It is comprehensible that language knowledge and learning ability derives from the learners' cultural activity, and consequently all learning is co-constructed in real life, and nothing is ever gained out of the society. For mental function, there is a role of applying scaffolding instruction in critical thinking, but more problems arise from the virtual language learning environment.

In peer-to-peer learning, scaffolding instruction tends to engage students more than formal instruction by a person in authority. For example, Second Life and other virtual reality multiplayer "games" are currently being explored by teachers as possible learning environments. Facebook provides an excellent space for collaborative group work between students. The popularity of Twitter, Blogs and Wikis provide a venue for self-publishing which, in turn, results in the sense of responsibility for producing information and acquiring knowledge aside from the mass media. This is also the new scaffolding resource in cultural and mental level, which leads to a specific learning of critical thinking in virtual language instruction. Therefore, Ruiz (2000) concludes that scaffolding instruction can help learners feel that their work is valued and can prepare them to be active contributors to a community of practice. Self-publication can also be used to encourage group or self-reflection. However, not all students are comfortable with self-publication. They may feel self-conscious about stating their opinion or fear of criticizing others. However, the setting up, monitoring and managing of these tools can be extremely time-consuming, and the constant evolution of these applications is in itself demanding.

In effect, individualized scaffold instruction is beneficial to language learners but it is the biggest disadvantage for the teacher since it is time-consuming to develop the supports and assistant lessons to meet the needs of each individual. Thus, it would be challenging for the instructors to design and implement the individualized scaffolds in a virtual classroom with a large number of students. For another, if the instructors are not properly trained, they may not apply 
the appropriate scaffolding instruction and therefore they may not bring the scaffolding strategy into full play. Also, it is required that the instructors dispense with the authority over the learners to control and monitor the virtual classroom and allow them to make errors when necessary. It is hard for them to give up the traditional teaching models to adopt the new scaffolding instruction in virtual settings.

\section{CONCLUSION}

As mentioned above, Scaffolding Instruction is a teaching model that helps learners understand specific knowledge and meaning by providing a set of appropriate conceptual framework. With the help of this conceptual framework, learners can explore and solve new problems independently and construct meaning independently. In virtual language learning, the autonomy in this framework is needed to develop learners' further understanding of problems in cooperative learning, quality control and critical thinking. That is, the framework should be established according to the "nearest development area" of their intelligence, so their intelligence can be continuously promoted from one level to another through the supporting role of this scaffold. The scaffolding strategy makes language teaching and learning proceed with the development of the independence. Thus, the process of virtual language learning turns out to be more learner-centered and competence-focused.

In conclusion, even if the use of scaffolding as a teaching strategy involves a lot of challenges to language instructors, the positive impact of scaffolding instruction on virtual language learning should not be ignored. The effect of good teaching, ahead of development, can optimize the virtual language learning. A number of scaffolding strategies and tools can be applied to provide rigorous, deep, and responsible education for students who need to develop their ability to learn a language conceptually, academically and linguistically. However, these technologies pose new challenges for the educators and raise issues about privacy and how to integrate them into the formal learning environment. They also set a benchmark that students use to judge the traditional learning environment. For virtual language learning, there will be still a long way to go.

\section{ACKNOWLEDGEMENTS}

This work was financially supported by the Foreign Language Teaching Project of Philosophy and Social Science Research in Jiangsu Province of China, "Research on Foreign Language Teaching Model Based on SPOC in Intelligent Background”. (Project Number: 2019SJB997)

\section{REFERENCES}

[1] Bransford, J., Brown, A. \& Cocking, R. (Eds.). (1999). How People Learn: Brain, Mind, Experience, and School (pp. 20-28). Washington, D.C.: National Academy Press.

[2] Bruner, A. Jolly and K. Sylva (Eds.). (1983). Play: Its Role in Development and Evolution (pp. 277-285). Harmondsworth, England: Penguin Books.

[3] Donato, R. (1994). Collective scaffolding in second language learning. In J.P. Lantolf and G. Appel (eds.) Vygotskian Approaches to Second Language Research (pp. 33-56). Norwood, NJ: Ablex.

[4] Gibbons, P. (2002). Scaffolding Language, Scaffolding Learning (pp. 27-28). Portsmouth, NH: Heinemann.

[5] McKenzie, Jamie. (1999). "Scaffolding for Success". From Now On: The Educational Technology Journal 9, no. 4. http://fno.org/dec99/scaffold.html.

[6] Moll, L.C. (Eds.). (1990). Vygotsky and Education: Instructional Implications and Applications of Socio-historical Psychology (pp. 77-85). Cambridge: Cambridge University Press.

[7] Pierce, B. (1995). Social identity, investment, and language learning. TESOL Quarterly, 29 (1), 9-10.

[8] Rogoff, B. (1995). Observing sociocultural activity on three planes: Participatory, appropriation, guided participation, and apprenticeship. In J. Wertsch, P. del Rio and A. Alvarez (eds) Sociocultural Studies of Mind (pp. 139-164). New York: Cambridge University Press.

[9] Rubin, J. (1975). What the 'good language learner' can teach us. TESOL Quarterly, 9, 41-51.

[10] Ruiz de Velasco, J. and Fix, M. (2000). Overlooked and Under-served: Immigrant Students in U.S. Secondary Schools (pp. 45-55). Washington, D.C.: The Urban Institute.

[11] Vygotsky, L.S. (1978). Mind in Society (pp. 2-28). Cambridge, MA: Harvard University Press.

Zhengxia Liu, female, was born in Huai'an Jiangsu Province in China in 1973 and graduated from Nanjing University of Science and Technology with a master's degree in English Linguistics and Literature in 2007. She has been working as an associate professor in Huaiyin Institute of Technology, studying cognitive linguistics and language education. Email:158194736@qq.com

Jie Hua (the Corresponding Author), female, was born in Huai'an Jiangsu Province in China in 1981 and graduated from Nanjing University with a master 's degree in English Linguistics and Literature in 2010. She has been working as a lecturer in Huaiyin Institute of Technology, studying cognitive linguistics and language education. Email:9441002@qq.com 
Zixu Zhang, male, born in Huai'an, Jiangsu Province in China in 2000, is studying his bachelor' degree in North China Power Electric University in Beijing, majoring in Computer Engineering. He has been doing research on Internet of Things with the main interest in Cyberspace Security. Email:1768216905@qq.com 